\title{
Neutron Activation Analysis of Microleakage Around a Hydrophobic Composite Restorative
}

\begin{abstract}
W. H. DOUGLAS, C. J. CHEN, and R. G. CRAIG 48109

Neutron activation analysis with dysprosium as a tracer was employed to determine quantitatively the microleakage around the restorations of an experimental hydrophobic composite, as well as a commercial composite. Only a negligible uptake of tracer was obtained for the experimental composite, whereas a five-fold uptake was recorded for the commercial composite. Capillary penetration of fluid around a restoration could be greatly reduced by using a hydrophobic composite.
\end{abstract}

Department of Dental Materials, School of Dentistry, The University of Michigan, Ann Arbor, Michigan

J Dent Res (59)9:1507-1510, September 1980

\section{Introduction.}

Water taken up at the site of a composite restoration may be subdivided into two types. At the margins, liquid (saliva, etc.) that flows between the tooth and the restoration may be termed capillary liquid. The driving force for this capillary penetration between two solids has been shown by O'Brien et al. ${ }^{1}$ to be a function of the free energy changes at the two solid-liquid interfaces.

If the change in free energy is negative, spontaneous penetration of fluid will occur, while if positive, pressure would be needed to force the fluid into the capillary space. Therefore, the use of a hydrophobic composite could possibly prevent capillary penetration around restorations even in the absence of chemical bonding.

When composites are used, liquid (water from saliva) may also be taken up by the bulk of the restoration as dispersed water by a molecule-by-molecule invasion of the composite.

In developing a satisfactory bond between a restoration and the tooth, the capillary water is eliminated. This condition has

Received for publication December 13, 1978 Accepted for publication September 14, 1979

This study was supported by Research Grant DE-04050 from the National Institute of Dental Research, National Institutes of Health, Bethesda, MD 20205. been approached by using the acid etch technique on the enamel. Efforts have also been made to bond the composite to dentin. However, even if complete bonding were achieved, dispersed water would be taken up, and thus the hydrolytic stability and hydrophobic qualities of the polymer are important.

Many techniques have been developed in attempts to assess quantitatively the microleakage around dental restorations for various materials and conditions. ${ }^{2}$ Neutron activation analysis is probably the best technique available that is quantitative. This technique was adapted for studying microleakage in vivo and in vitro first by Going et al., 3 using manganese as a tracer. An improved method has been achieved since then by Meyer et al. ${ }^{4}$ with dysprosium as a tracer. This modification showed the least variation in results and allowed the fastest activation and counting procedure.

It was the purpose of this study to evaluate the contribution that a hydrophobic composite might make to the reduction of marginal leakage. A later study will report on the usefulness of a hydrophobic system that includes the acid etch technique and bonding agents.

\section{Materials and methods.}

Two types of filling materials were used: an experimental hydrophobic composite and a commercial composite.* The hydrophobic composite was formulated using octafluoropentyl methacrylate and a bisphenol adduct, which has been described in a previous publication. ${ }^{5}$

Forty-five lower human incisors, which had been stored in glycerol-alcohol, were brushed and cleaned by prophylaxis with pumice and a bristle brush. The teeth were examined for caries and stored in air-tight

*Adaptic, Johnson and Johnson Dental Products Co., New Brunswick, NJ 
polyethylene containers. The teeth were weighed, and their standard deviation was $10 \%$ of the mean weight showing a good standardization of overall tooth size. Using a random number generator, a group of five teeth were removed, and the remaining 40 teeth had a standardized cavity cut in the labial face.

The principle of cavity design was to obtain the longest enamel-composite interface, given the small size of the teeth and anticipating that the amount of fluid uptake would be very small. Therefore, an approximately square outline was cut following the spade-like form of the incisor, about $3 \mathrm{~mm} \mathrm{x}$ $3 \mathrm{~mm}$, with rounded internal angles, and extending just into the dentin. A number 556 bur was used at high speed and ample coolant was supplied. Enamel margins were finished using a finishing bur at slow speed. The teeth were then randomly separated into two groups and stored in air-tight containers to prevent desiccation.

All the teeth with prepared cavities in both groups were replicated using a silicone impression material. $\dagger$ Models of each tooth and cavity were made using high quality polyethylene wax. $\$$ Thus, all the prepared teeth in both groups had anatomically matched controls in a hard polyethylene wax. The enamel margins of the preparations were not etched with acid. Each tooth and its control were filled with composite at the same time from the same mix. Polyethylene sheeting, 1/1000 inch thick, which had been cut into strips, was used as a matrix band. The strip and the morphology of the tooth controlled the contour of the restoration. Only minimal finishing with stones ${ }^{\circ}$ was carried out when necessary at the margins of the restoration.

The teeth, therefore, constituted three groups. The first group, including the controls, had been filled with the experimental composite. The second group and its controls had been filled with the commercial composite. The test teeth in the first and second groups were coated with polyethylene wax to within $0.5 \mathrm{~mm}$ of the margin. The third group comprised five

\footnotetext{
$\dagger$ President, Regular, Pacemaker Corp., Portland, $O R$

FInternational Wax Refining Co., Valley Stream, NY

OShofu Dental Mfg. Co., Ltd., Kyoto, Japan
}

unprepared teeth, which were completely waxed to provide a baseline for the study. All the teeth were soaked for one $h$ in a dysprosium nitrate $\left[\mathrm{Dy}\left(\mathrm{NO}_{3}\right)_{3} \cdot 5 \mathrm{H}_{2} \mathrm{O}\right]$ solution $\$(1 \mathrm{gm} / 100 \mathrm{ml})$. Teeth were wiped off, coated with a utility wax, and stored in individual polyethylene bags which were then thermosealed for irradiation. Irradiation was carried out for $30 \mathrm{sec}$ in a nuclear reactor\# with a flux of $2 \times 10^{12}$ neutrons/ $\mathrm{cm}^{2} / \mathrm{sec}$. After irradiation, counting was delayed for two-and-one-half $\mathrm{min}$. Each specimen was counted for $40 \mathrm{sec}$ with a germanium low-energy photon spectrometer." The background was corrected and counts were analyzed by a computerbased multi-channel analyzer.** The tracer uptake was determined by comparison with a standard solution of dysprosium $(100 \mu \mathrm{g} /$ $\mathrm{ml}$ ).

\section{Results.}

The uptake of tracer for both the experimental and commercial composites, based on 20 samples of each, is shown in Table 1 . The average total uptake by the teeth with the experimental composite and the commercial composite was 8.26 and 13.40 $\mu \mathrm{g} /$ tooth, respectively. The least significant difference (LSD) test ${ }^{6}$ was used to test for a significant difference between these two means. A LSD value of 1.65 was obtained at the 0.01 level and indicated that a significant difference existed.

The uptake by the wax replicas containing restorations of the filling materials was about the same for both composites. The average values were 4.42 and $4.73 \mu \mathrm{g} /$ restoration, and no significant difference was shown at the 0.05 level.

An average baseline value of $2.55 \mu \mathrm{g} /$ tooth was established for teeth without filling materials using five samples. Zero uptake was obtained for teeth that were not soaked in tracer solution.

\section{Discussion.}

The baseline values determined from

$\S$ Pfaltz and Bauer, New York, NY

\#phoenix Memorial Laboratory, University of Michigan, Ann Arbor, MI TN

"Model 8113-16350, Ortec, Inc., Oak Ridge,

**Model 4420, Nuclear Data, Palatine, IL 
TABLE

TRACER UPTAKE BY AN EXPERIMENTAL AND A COMMERCIAL COMPOSITE

\begin{tabular}{|c|c|c|c|c|c|}
\hline & \multicolumn{2}{|c|}{ Experimental Composite } & \multicolumn{2}{|c|}{ Commercial Composite* } & \multirow[b]{2}{*}{$\begin{array}{c}\text { Baseline } \\
(\mu \mathrm{g} / \text { tooth })\end{array}$} \\
\hline & $\begin{array}{c}\text { Total Uptake } \\
(\mu \mathrm{g} / \text { tooth })\end{array}$ & $\begin{array}{c}\text { Uptake by Sorption } \\
(\mu \mathrm{g} / \mathrm{replica})\end{array}$ & $\begin{array}{l}\text { Tota1 Uptake } \\
(\mu \mathrm{g} / \text { tooth })\end{array}$ & $\begin{array}{c}\text { Uptake by Sorption } \\
(\mu \mathrm{g} / \mathrm{replica})\end{array}$ & \\
\hline & $\begin{array}{r}10.54 \\
8.80 \\
7.33 \\
10.71 \\
4.49 \\
7.98 \\
9.68 \\
6.38 \\
5.71 \\
4.51 \\
8.61 \\
10.75 \\
8.97 \\
8.21 \\
9.88 \\
6.46 \\
7.15 \\
11.49 \\
8.33 \\
9.21\end{array}$ & $\begin{array}{l}3.65 \\
4.36 \\
4.20 \\
4.56 \\
3.16 \\
4.33 \\
4.78 \\
4.16 \\
6.13 \\
4.96 \\
5.12 \\
4.96 \\
5.53 \\
3.96 \\
3.27 \\
4.28 \\
5.07 \\
3.88 \\
4.01 \\
4.03\end{array}$ & $\begin{array}{r}15.52 \\
10.16 \\
11.81 \\
10.86 \\
17.95 \\
12.87 \\
11.80 \\
10.26 \\
14.57 \\
12.49 \\
13.58 \\
13.14 \\
18.66 \\
17.96 \\
9.39 \\
12.87 \\
12.24 \\
10.72 \\
18.59 \\
12.52\end{array}$ & $\begin{array}{l}2.94 \\
3.13 \\
3.47 \\
7.66 \\
5.33 \\
3.64 \\
5.48 \\
5.60 \\
5.35 \\
4.66 \\
7.48 \\
7.66 \\
5.14 \\
5.18 \\
5.01 \\
4.19 \\
2.87 \\
3.14 \\
3.68 \\
3.05\end{array}$ & $\begin{array}{l}2.45 \\
3.10 \\
2.29 \\
2.44 \\
2.48\end{array}$ \\
\hline Mean & $\begin{array}{l}8.26 \\
(2.03)^{+}\end{array}$ & $\begin{array}{c}4.42 \\
(0.74)\end{array}$ & $\begin{array}{l}13.40 \\
(2.91)\end{array}$ & $\begin{array}{c}4.73 \\
(1.56)\end{array}$ & $\begin{array}{c}2.55 \\
(0.32)\end{array}$ \\
\hline $\begin{array}{c}\text { Net } \\
\text { Uptake }\end{array}$ & \multicolumn{2}{|c|}{1.29} & \multicolumn{2}{|c|}{6.12} & \\
\hline
\end{tabular}

*Adaptic, Johnson and Johnson Dental Products, New Brunswick, NJ

+ Values in parentheses are standard deviations.

teeth coated with wax, but without filling materials, were fairly constant, as shown by the relatively small standard deviation of 0.32 . In addition, no dysprosium was found in the unsoaked teeth. These results confirm that dysprosium is a suitable tracer for the study of microleakage around non-metallic dental restorations. The amount taken up by the baseline teeth coated with polyethylene wax after soaking probably resulted from the sorption of tracer solution by the wax surface.

The lower total uptake for the experimental composite compared with the commercial composite is attributed to the hydrophobic character of the experimental composite. The experimental composite, with the polymer portion based on a fluorocarbon analog of methacrylate, was shown to be hydrophobic with an advancing contact angle of $156^{\circ}$ with water on a surface finished with 600 grit $\mathrm{SiC}$ paper. ${ }^{5}$ In comparison the advancing contact angle for the commercial composite was $58.7^{\circ}$ after finishing. 5

According to the previous study by O'Brien et al., ${ }^{1}$ a filling material with a contact angle greater than $130^{\circ}$ would be required in order for the free energy's change to be positive if the contact angle of water on enamel is taken to the $50^{\circ} .7$ Therefore, the experimental composite, having a contact angle of $156^{\circ}$ after finishing, should prevent or reduce the capillary penetration around the restorations. On the contrary, the commercial composite with a contact angle of about $59^{\circ}$ would give a negative free energy charge, and microleakage would be expected to occur. This observation is clearly shown in the results.

The wax replicas of each tooth provided a matched anatomical control and were made using polyethylene wax, which has a high contact angle with water of $110^{\circ}$. The penetration of liquid through the space between the wax and filling materials should 
be prevented or limited to an insignificant amount. This assumption is reasonable, judged by the result that the uptake of dysprosium was about the same for both composites. Therefore, the uptake by replicas of polyethylene wax and filling materials could be considered to be caused by sorption of the tracer solution by the filling material. Although the water sorption at equilibrium of the commercial composite is about four times that of the experimental composite, 5 this difference was not apparent by the uptake values in the present study, probably because of the short soaking time. This explanation is supported by additional observations that a three-fold increase in uptake for the commercial composite was observed when the samples were soaked for $12 \mathrm{~h}$.

The net uptake as a result of the penetration around the restoration only was obtained by subtracting the baseline value and the uptake by sorption of the restoration from the total uptake. Only a negligible uptake of $1.29 \mu \mathrm{g} /$ tooth was found for the experimental composite, whereas a value of $6.12 \mu \mathrm{g} /$ tooth was determined for the commercial composite. These data demonstrate that unlike commercial composites, the experimental hydrophobic composite allowed little microleakage.

This study suggests that a hydrophobic varnish, in combination with a hydrophobic composite, could further prevent the penetration of liquid.

\section{Conclusions.}

Microleakage around an experimental hydrophobic and a commercial composite was quantitatively determined using neutron activation analysis and dysprosium as a tracer. The experimental composite showed only a negligible penetration of liquid into the space between the restoration and the cavity walls, which was attributed to its hydrophobic character. A significant marginal leakage of five times the uptake of the experimental composite was obtained for the commercial hydrophilic composite material. It appears likely that the hydrophobic quality of a material could be one useful factor, among others, that could be used to reduce clinical marginal leakage.

These results are considered sufficiently encouraging to test these principles by greater challenges to marginal leakage, including thermal cycling, mechanical cycling, and the penetration of fluids of reduced contact angles on tooth surfaces.

\section{REFERENCES}

1. O'BRIEN, W.J.; CRAIG, R.G.; and PEYTON, F.A.: Capillary Penetration Between Dissimilar Solids, $J$ Colloid and Interface Sci 26: $500,1968$.

2. GOING, R.E.: Microleakage Around Dental Restorations: A Summarizing Review, JADA $84: 1349,1972$.

3. GOING, R.E.; MYERS, H.M.; and PRUSSIN, S.G.: Quantitative Method for Studying Microleakage in vivo and in vitro, $J$ Dent Res 47: $1128,1968$.

4. MEYER, J.M.; DENNISON, J.B.; and CRAIG, R.G.: Improved Method of Neutron Activation Analysis for Microleakage Studies, J Dent Res $53: 356,1974$

5. DOUGLAS, W.H.; CRAIG, R.G.; and CHEN, C.J.: A New Composite Restorative Based on a Hydrophobic Matrix, $J$ Dent Res 58:19811986, 1979.

6. STEEL, R.G.D. and TORRIE, J.H.: Principles and Procedures of Statistics, New York: McGraw-Hill, 1960, p. 106.

7. UY, K.C. and CHANG, R.: An Approach to the Study of Mechanism of Adhesion to Teeth, in: Adhesive Restorative Dental Materials II. Bethesda: National Institute of Dental Research, 1965, pp. 103-128. 